\title{
THE
}

\section{Elevated potential for intraspecific competition in territorial carnivores occupying fragmented landscapes}

Pranav Chanchani

Brian D. Gerber

University of Rhode Island, bgerber@uri.edu

Barry R. Noon

Follow this and additional works at: https://digitalcommons.uri.edu/nrs_facpubs

The University of Rhode Island Faculty have made this article openly available. Please let us know how Open Access to this research benefits you.

This is a pre-publication author manuscript of the final, published article.

Terms of Use

This article is made available under the terms and conditions applicable towards Open Access Policy Articles, as set forth in our Terms of Use.

\section{Citation/Publisher Attribution}

Chanchani, P., Gerber, B. D., \& Noon, B. R. (2018). Elevated potential for intraspecific competition in territorial carnivores occupying fragmented landscapes. Biological Conservation, 227, 275-283. doi: 10.1016/j.biocon.2018.08.017

Available at: https://doi.org/10.1016/j.biocon.2018.08.017

This Article is brought to you for free and open access by the Natural Resources Science at DigitalCommons@URI. It has been accepted for inclusion in Natural Resources Science Faculty Publications by an authorized administrator of DigitalCommons@URI. For more information, please contact digitalcommons-group@uri.edu. 
Elevated potential for intraspecific competition in territorial carnivores occupying

\section{fragmented landscapes}

\section{Authors:}

Pranav Chanchani ${ }^{1,2,3^{*}}$, Brian D. Gerber ${ }^{4}$, Barry R. Noon ${ }^{1,2}$

${ }^{1}$ Department of Fish, Wildlife and Conservation Biology, Colorado State University, Fort Collins, 80523, USA.

${ }^{2}$ Graduate Degree Program in Ecology, Colorado State University, Fort Collins, 80523, USA

${ }^{3}$ Current affiliation: World Wide Fund for Nature, 172-B Lodi Estate, New Delhi, 110003, India.

${ }^{4}$ Department of Natural Resources Science, University of Rhode Island, Kingston, Rhode Island, 02881, USA.

* Corresponding author's email:

Pranav Chanchani: pranav.chanchani@gmail.com 


\section{Abstract}

2

3 The distribution of mammals is determined by a suite of endogenous and exogenous factors. In

4 territorial, polygynous species, like tigers (Panthera tigris), males endeavour to center their

5 space-use around female territories, repelling competitors from these areas. Competition among

6 males for females leads to increased mortality of both sexes and infanticide of unrelated cubs,

7 which can lead to population declines. We hypothesized that increased territorial overlap among

8 adult male tigers and elevated levels of inter and intra-sex competition would be manifest in

9 populations with male-biased adult sex ratios (ASR). We also assessed whether inter-sex variation in adult survival or degree of habitat connectivity resulted in skewed ASR. We

11 evaluated these hypotheses using camera trap data from three tiger populations occupying habitat

12 patches with varying levels of connectivity and ASRs. Data were analyzed using multi-state

13 occupancy models, where states were defined as habitat use by one or more male tigers, in sites

14 with and without female use. As predicted, in populations with male-biased or even ASR, we

15 found evidence for increased spatial overlap between male tigers, particularly around female

16 territories. Given parity in adult survival, habitat fragmentation likely caused male-biased ASR.

17 Our results suggest that the persistence of small tiger populations in habitat patches with male-

18 biased ASR may be especially influenced by behaviour-mediated endogenous demographic

19 processes that are often overlooked by managers. In habitat fragments with severely skewed

20 ASR, population recovery of territorial carnivores may require timely supplementation of

21 individuals to compensate for population losses from intra-specific competition.

22 Keywords: carnivores; intra-specific competition; fragmentation; multi-state occupancy; sex

23 ratio; survival

24 1. Introduction 
25 Adult sex ratio (ASR, male: female) is an important demographic parameter that influences both

26 individual behavior and population dynamics (Caswell, 2001; Haridas et al., 2014; Le Galliard et

27 al., 2005; Székely et al., 2014). Skewed or uneven sex ratios in animal populations can occur for

28 a variety of reasons, including sex differences in survival due to disproportionate costs of

29 reproduction for females and sex-biased immigration or emigration by males (Veran and

30 Beissinger, 2009). It has been hypothesized that ASR in many species may also be an artifact of

31 intrasexual competition, which can result in increased mortality or dispersal of the sex with

32 higher frequency in a population (Clutton-Brock et al., 2002; López-Sepulcre et al., 2009). Male-

33 biased sex ratios may result in increased aggression by males towards females, resulting in a

34 decline in their fecundity and survival with negative effects on population growth and

35 persistence (Barrientos, 2015; Grayson et al., 2014; Le Galliard et al., 2005).

In polygamous species, adult male territories often encompass the territories of multiple

37 females. Skewed ASR's have especially pronounced impact on the behavior and demography of

carnivores - for example, intraspecific predation has been documented in at least 14 large

carnivore species (Polis, 1981). This typically involves infanticide or killing of younger and

40 immature animals and cubs by adults, typically on account of territorial disputes, and has been

41 shown to substantially reduce population size (Polis, 1981). When first acquiring a female

42 territory, adult male carnivores are known to seek out and kill non-related juveniles to increase

43 their reproductive fitness (Barlow et al., 2009; Hrdy, 1979; Persson et al., 2003). Additive

44 mortality from intraspecific competition and infanticide may be especially detrimental for small

45 populations of several terrestrial carnivores that are already vulnerable to extinction (Chapron et 46 al., 2008). 

area requirements, habitat loss and real or perceived conflicts with humans (Ripple et al., 2014). Tiger (Panthera tigris) populations are especially at risk because of a lucrative illegal global 50 trade in their pelts and other body parts -- as few as 3900 individuals may now exist in the wild 51 (WWF 2016) and remnant populations are small -- there are now probably fewer than 20 52 populations $>50$ individuals. While the risk of local extinction is primarily driven by illegal 53 hunting and habitat loss and fragmentation, several endogenous factors may exacerbate 54 extinction risks of small populations. For example, strong territorial behavior can aggravate the 55 demographic issues of small and fractured populations. Intraspecific competition and aggression, 56 especially in areas with male-biased ASR can increase the extinction risks of small populations

57 (Barlow et al., 2009). Adult male tigers fiercely defend their territories from competing males to retain access to breeding females (Horev et al., 2012; Sunquist, 1981). If a dominant territorial 59 male is displaced by a rival, the outcome is often infanticide of the former's cubs by the later 60 (Barlow et al., 2009; Smith and McDougal, 1991); this enables females to become receptive 61 mates more quickly to the new dominant male. The harem size of male tigers and degree to 62 which breeding males are able to maintain stable territory sizes can profoundly impact 63 population dynamics and extinction rates (Horev et al., 2012).

Several aspects of the social behavior of tigers, including a polygynous mating system, territoriality and dispersal, are relevant to demography, behavior and space-use. Female tigers select territories to secure access to adequate resources to protect and raise young (e.g., sufficient 67 prey, cover and water), and males compete for territorial dominance of one or more female territories (Goodrich et al., 2008; Smith, 1993; Smith and McDougal, 1991; Sunquist, 1981). In

69 South Asia, male tiger territory size is usually $>100 \mathrm{~km}^{2}$, while females maintain territories 
70 between $10-30 \mathrm{~km}^{2}$ (Sunquist, 1981). Dispersal is also typically male-biased: adult females

71 tolerate their female offspring establishing territories in close proximity to their own, but male

72 offspring are driven away. Young males in search of new territories often disperse over large

73 distances and commonly experience aggressive interactions with other males (Reddy et al., 2016;

74 Smith, 1993). Although published information is sparse, ASR (Males:Females) between 1:2 and

75 1:3 have generally been reported from South Asia (Majumder et al., 2017; Sunquist, 1981).

76 Some studies in India, however, have revealed that densities and sex ratios of adult tigers can

77 vary widely (Sadhu et al., 2017), and may even be male-biased (Chanchani et al., 2014a).

Considering the social and population biology of tigers raise several questions relevant to

79 tiger spatial ecology, especially in fragmented landscapes with small populations. Foremost is

80 whether there is a high potential for intraspecific competition, infanticide and antagonism among

81 tigers due to high levels of habitat use (i.e., site occupancy) by multiple male tigers, with and

82 without female tigers. Second, does variation in ASR help understand patterns of fine-scale

83 habitat use by male tigers, such that we might expect higher potential intraspecific competition in

84 local populations with male-biased ASR? Lastly, can inter-site variations in ASR for tiger

85 populations be attributed to sex-biased emigration, limited habitat connectivity, or to differences

86 in sex-specific adult survival rates?

87 To evaluate these hypotheses, we analyze an extensive capture-recapture dataset for a 88 tiger population in the Dudhwa Tiger Reserve (DTR) - a 1,200 $\mathrm{km}^{2}$ protected area within the 89 Central Terai Landscape (CTL) in North India. DTR consists of three disjoint protected areas 90 (subsequently referred to as, 'sites'). Sites are characterized by strong gradients in tiger density, 91 habitat connectivity and variation in ASR — ranging from highly connectivity, high density and 92 female-biased ASR - to isolated, low density and male-biased ASR (Chanchani, 2016). Given 
93 the polygynous mating-system in tigers, sites with an even sex ratio, or those with more adult

94 males than females were deemed as having male-biased ASR. We tested the null hypothesis that

95 the probability of habitat use (fine-scale occupancy) by one or more male tigers would be

96 similar, regardless of a site's ASR. Alternatively, we had two general predictions about the fine-

97 scale space-use by male tigers in sites with male-biased ASR. First, we predicted lower overall

98 male habitat use, i.e., extensive habitat areas that are distant from female territories will not used

99 by male tigers (hypothesis 1 in Table 1). Second, we predicted high competition among males to

100 secure access to female territories would be manifest in the following space-use patterns: (a) high

101 male-use of tigers in locations with no female use (specifically along the margins of female

102 territories; hypotheses 2 and 4, Table 1); and (b) high probability of multiple rather than single

103 male-use in locations with female-use (hypotheses 3 and 5, Table 1). This is expected because

104 harem sizes are smaller in areas with male-biased ASR, and multiple males are thus expected to

105 compete intensively for access to each female (Table 1). Finally, to investigate the factors

106 contributing to male-biased ASR in sites with limited connectivity, we also assessed if male

107 distribution was affected by inter-sex differences in movement probabilities (stemming from

108 differences in dispersal behavior and habitat fragmentation). When adult survival is similar for

109 both sexes, or when female survival > male survival -- male-biased ASR in populations can be

110 an artifact of high rates of female emigration, and/or differential male immigration from

111 surrounding populations (Smith, 1993). 


\section{Materials and Methods}

118

119

120

\subsection{Description of study area}

121 Dudhwa Tiger Reserve is located in the Terai-Duar savannas and grasslands ecoregion that spans 122 areas of Nepal, India, Bhutan and Bangladesh (Olson et al., 1998; Fig. 1). DTR is comprised of 123 Dudhwa National Park $\left(\sim 700 \mathrm{~km}^{2}\right)$, Katerniaghat Wildlife Sanctuary (WLS; $\left.450 \mathrm{~km}^{2}\right)$ and 124 Kishanpur WLS ( 200 km²), established in 1977, 1975 and 1972 respectively. DTR's most 125 productive wildlife habitats, grasslands and wetlands, comprise approximately $18 \%$ of the overall 126 area. Other habitats include dry deciduous Sal (Shorea robusta) forests, and mixed-dry deciduous

127 forests and teak (Tectonia grandis) plantations. Within India, the last remnant patches of the once128 extensive grassland-wetland mosaics that characterize the CTL are now restricted to small areas in 129 and around DTR. The reserve's management has undergone drastic changes over the past 150 130 years. Through the $19^{\text {th }}$ century and until about 1960, large forest tracts were exclusive hunting 131 blocks for India's colonial administrators and Indian royalty. Other areas were intensively managed 132 to supply high-grade sal (Shorea robusta) timber (Strahorn, 2009).

The three protected areas (PAs) of DTR vary in their degree of connectedness with other 134 tiger habitats in India and Nepal. Kishanpur Wildlife Sanctuary is embedded within a larger tiger 135 habitat patch $\left(\sim 1400 \mathrm{~km}^{2}\right.$ Pilibhit forest complex in India) and connected with Shuklaphanta 136 Wildlife Sanctuary in Nepal, via the Sharda River corridor. Katerniaghat WLS is connected to the $137968 \mathrm{~km}^{2}$ Bardia National Park via the $40 \mathrm{~km}$ long Khata corridor (along the Karnali River). 138 Connectivity between Dudhwa National Park and Laljhari and Basanta community forests in Nepal 139 has been severely degraded due to land use change and expanding human settlements in recent 140 decades (Chanchani et al., 2014b; Joshi et al., 2016; Kanagaraj et al., 2013). Finally, tiger density 
141 and ASR in DTR's three PA's vary extensively. The highest tiger density (4.66 and 4.92 tigers/

$142100 \mathrm{~km}^{2}$ ) and most female-biased ASR (adult males $=29 \%$ of population) were recorded from

143 Kishanpur WLS in 2013 (Chanchani et al., 2014a; Table 2). In contrast, tiger densities were lower

144 in Katerniaghat WLS (4.72 and 2.22 tigers/100 km2, (61\% and 33\% males in 2012 and 2013

145 respectively) and Dudhwa National Park (1.05 and 1.89 tigers/100 km2, 58\% and 47\% males in

1462012 and 2013) (Jhala et al. 2015; Chanchani 2016; Table 2). There is negligible uncertainty

147 associated with adult sex-ratios because estimates come from a near-census of the target

148 populations (Appendix A).

$149 \quad 2.2$ Camera Trap Sampling

Between November 2011 and June 2013, we conducted extensive camera-trap surveys to

151 assess the status of tigers in the CTL (Fig. 1). We used a grid-based sampling design and

152 positioned pairs of cameras at intervals of approximately $2 \mathrm{~km}$ within tiger habitats. Camera traps

153 were placed along forest trails or water courses to maximize detection probability. These surveys

154 were completed in $\leq 60$ days to meet the demographic closure assumption of occupancy and

155 capture recapture models (Karanth et al., 2002). At each location, cameras were operated from 14-

15656 days. Overall, 304 locations were sampled with camera traps from November 2011- May 2012,

157 and 380 locations were sampled from November - June 2013 (Table 2).

158

159

2.3 Data Processing, Model Formulation and Analysis

To evaluate our a priori hypotheses, we fit multi-state occupancy models to our camera trap data (Nichols et al., 2007). Camera trapping data have been traditionally analyzed in a mark-

162 recapture framework to estimate demographic parameters (such as abundance and survival), but

163 recent extensions of these methods allow estimates of patch occupancy and species co-occurrence 
164 (Nichols et al., 2007; O'Connell and Bailey, 2011). We apply multi-state occupancy models to test hypotheses about tiger distribution in the context of variable habitat connectivity (Johnsingh et al., 2004; Kanagaraj et al., 2013; Wikramanayake et al., 2004) and ASR within habitat patches in our study area.

Photo-captured adult tigers were individually identified from photos by three independent observers and by using pattern recognition software (Hiby et al., 2009). The sex of all tigers was discernible from the photos which allowed us to assign habitat-use states by sex and individual. We defined a sampling occasion as a 14-day period corresponding to the duration over which tiger spray scent (used for territorial marking) remains detectable (Smith et al., 1989). At each camera trap location and on every sampling occasion, male tiger captures were assigned to one of five habitat-use states. These states indicated probability of use of locations by single $(\psi)$ or multiple $\left(\psi^{\prime}\right)$ male tigers, in the context of female use (presence/absence) $(f ;$ Table 1$)$. Tiger habitat use states were defined as: State 1 , no male use $\left(1-\psi-\psi^{\prime}\right)$; State 2, location use by a single male and no female use $(\psi \times(1-f))$; State 3, location use by single male, and any female $(\psi \times f)$; State 4 , use of location by multiple males and no female use $\left(\psi^{\prime} \times(1-f)\right)$; and State 5 , use by multiple males, and female use $\left(\psi^{\prime} \times f\right)$. Notations in parentheses are mathematical probability statements uniquely identifying each state. Multi-state occupancy models allow for state uncertainty. We accounted for non-detection of male tigers by estimating misclassification probabilities - for example, we might record the presence of a male tiger during a 14-day occasion (observe state 2) even though females were also present (true state 3 ); the probability of this misclassification is $p \_3 \_2$ (Fig. 2). We estimated model parameters using a hierarchical Bayesian multi-state occupancy model (Kery and Schaub, 2012; Royle and Dorazio, 2008). The true (latent) state of each location (trap station), $z$, can take on state values equal to $1,2,3,4$ or 5 , 
corresponding to the five habitat use states. Latent occurrence, $z$, is modeled by estimating $\Omega_{i}$, the state vector describing the probability that site $i$ is in one of the five states. The observation process describes how the true state $z$ is linked with the observations, $y_{i j}$, the observed states of tiger habitat use at site $i$ and occasion $j$. The conditional relationship between $y_{i j}$ and $z$ is described by a categorical distribution with the $\theta_{z}$, representing the observation matrix (Fig. 2). The elements of the observation matrix are the probabilities of observing tiger use in each of the five states. Diagonal elements are the probabilities of correct classification and off-diagonals elements are the probabilities of misclassification. The probabilities in each row of the observation matrix sum to 1 . Detection probabilities were allowed to vary among survey occasions ( 2 week-long periods). Because sex-specific fine-scale habitat use by tigers was unknown, we specified vague logit normal priors for $\psi$ and $\psi^{\prime}$ (Fig. 2). The prior for $f$ was modeled using a beta distribution prior, implying a uniform probability between 0 and 1 . We used Dirchlet priors to describe the distribution of elements within observation array rows $\left(\mathrm{p}_{, \mathrm{n} \_\mathrm{k}} p_{1 \_k}, p_{2 \_k}, p_{3 \_k}, p_{4 \_k}\right.$, and $\left.p_{5 k}\right)$, where $n$ represents the true state of a site and $k$ represents the observed state. The Dirchlet distribution satisfies the requirement that the elements of each row of the observation array sum to 1 (Hobbs and Hooten, 2015; Kery and Schaub, 2012). We fit our Bayesian model using Markov chain Monte Carlo (MCMC) algorithms implemented in program JAGS (Plummer, 2003) linked to R (R Development Core Team). We separately analyzed data for three PA's in DTR in each of the two survey years, with the exception of Dudhwa National Park, (2012), where the survey period was short (14 days). Each data-set was fit using three chains (to assess parameter convergence), each with 100,000 MCMC iterations, and a burn-in value of 10,000.

\subsection{Model Support and Evaluation}


211 and model support, we used a one-sided test based on Bayesian $p$ values. Specifically, to test

212 whether a given prediction was supported - for example, that probability of multiple-male

213 tigers using a location would be higher at sites with male-biased ASR $\left(\psi^{\prime}{ }_{\text {site } 2} \times f_{\text {site } 2}\right)$ than in sites

214 with female-biased ASR $\left(\psi^{\prime}\right.$ site $\left.1 \times f_{\text {sitel }}\right)$ — we derived:

215

216

$\sum_{i=1}^{n . m c m c}\left(\left(\psi^{\prime}{ }_{\text {site } 2} \times f_{\text {site } 2}\right)-\left(\psi^{\prime}{ }_{\text {sitel }} \times f_{\text {site } 1}\right)\right)>0 / n . m c m c$,

where $n . m c m c$ is the number of MCMC iterations. If the posterior distributions were exactly the

219 same, we expect a value of 0.5 (i.e., given any value from $\left(\psi^{\prime} \times(f)\right)_{\text {site } 2}$ compared to $\left(\psi^{\prime} \times(f)\right)_{\text {site } 1}$

$220,50 \%$ will be greater). Values $>0.5$ indicate support for the hypothesis. In a scenario where all

221 samples in $\left(\psi^{\prime} \times(f)\right)_{\text {site } 2}>\left(\psi^{\prime} \times(f)\right)_{\text {site } 1}$, we expected a Bayesian $p$ value of 1 .

222 We assessed model fit via a posterior predictive check where simulated data sets for each

223 site/year are compared with the original data sets (Gelman and Hill, 2007). We examined

224 whether the probabilities of the observed data were more extreme relative to the simulated data.

225 Posterior predictive checks revealed no evidence of lack of fit because test statistics based on the

226 observed data were not more extreme than test statistics calculated from the simulated data

227 (Appendix B).

228

229

\subsection{Estimating Survival}

We used Cormack-Jolly-Seber (CJS) models to estimate apparent annual survival rates for

231 adult tigers (Lebreton et al., 1992). We refer to 'apparent' survival because mortality cannot be

232 discriminated from permanent emigration and survival for at least one year (Karanth et al., 2006). 
233 Data on tiger survival were available from a four-year (2010-2014) capture-recapture data set. To

234 assemble capture histories for open population models, we used data from two separate sources.

235 Data for 2012 and 2013 came from our camera trap studies. For the years 2010 and 2014, we

236 identified individual tigers from published photo databases of individual tigers captured in DTR

237 (Jhala et al., 2015, 2011). We separately estimated probabilities of apparent survival $(\Phi)$ and

238 recapture probabilities $(p)$ for the three PA's allowing for $\Phi$ and $p$ to be constant, vary by sex or 239 year, or both.

240

241

242

243

244

245

246

247

248

249 sites.

250

251

252

253

254 biased sex ratio and habitat connectivity (0.24, median, Kishanpur WLS). As such, we did not find 255 support for the null hypothesis that habitat use by male tigers would be similar in sites with and 256 without male-biased ASR (Table 3) Interestingly, the probability of habitat use by a single male 
257 tiger and no female tigers (State 2; $(\psi \times(1-f))$ was fairly similar; parameter uncertainty was

258 relatively large and thus difficult to provide clear evidence of any differences.

259 Given a tiger population occurs in relatively good habitat with the necessary resources and 260 stable territories and social dynamics, we would generally expect that most habitat use could be 261 described as State $3(\psi \times f)$, a single male tiger with one or more females present. As such, it is 262 interesting that we found the highest median probabilities of habitat use in State 3 were only 0.38

263 and 0.4, occurring at Kishapur WLS. However, these probabilities are still higher than those from 264 the other sites, which had lower habitat connectivity and higher male-biased/even ASR, thus 265 supporting our hypothesis..

266 We found empirical support of potential intraspecific competition, infanticide, and 267 antagonism among tigers with relatively high habitat use by multiple male tigers with females 268 (State 5; $\left.\left(\psi^{\prime} \times(f)\right)\right)$ or without females (State $\left.4 ; \psi^{\prime} \times(1-f)\right)$. The probability of a location being in 269 state 4 or 5 ranged across sites from 0.03 to 0.2 (medians). Furthermore, model estimates also 270 indicated support for our hypotheses about increased potential for intraspecific competition in sites 271 with male-biased/even ASR. Median estimates of habitat use in state 4 were 1.5-2 times higher in 272 sites with male-biased/even ASR, than in Kishanpur, a site with a female-biased ASR (Table 3; 273 Fig. 3). However, we note that ASR was male-biased in Katerniaghat WLS in 2012 but female274 biased in 2013. In general, probabilities of fine-scale habitat use by multiple male tigers and 275 females (State $\left.5\left(\psi^{\prime} \times(f)\right)\right)$, appeared to be generally low and similar across sites, regardless of 276 ASR, suggesting that dominant males may be highly effective in warding off territorial intrusions 277 by rivals. However, parameter uncertainty makes it difficult to statistically differentiate possible 278 differences. 


\subsection{Survival Estimates}

Apparent survival for adult male and female tigers were similar in the three sites, suggesting that differential survival of adult male and female tigers is unlikely to be the key factor underlying variation in ASR in these sites. Estimates of male and female survival were very similar in two of our three study sites (Fig. 4). Point estimates of female survival was highest in Kishanpur WLS $(\Phi=0.85, \mathrm{SE}=0.06)$ and were $10-15 \%$ lower in our two other study sites with lower habitat connectivity. However, the confidence intervals overlapped across sites providing no clear statistical evidence of a difference. Estimates of male survival were similar in all three sites $(\Phi=0.65)$. Overall, models with sex-specific differences in survival were weakly supported relative to other models that assumed constant survival probabilities for males and females. (Appendix C).

\section{Discussion}

Our study casts light on how space use of a territorial carnivore is influenced by the species territorial behavior and intra-specific interactions. By modeling shared space use by tigers at point locations (camera trap stations), we are also able to investigate how heterogeneity in species occurrence may also be influenced by endogenous factors, in addition exogenous variables (for example abundance, vegetation attributes, and human presence) that are typically used to explain species occurrence (Barber-Meyer et al., 2013; Sunarto et al., 2012). We highlight three patterns in inter-site variations in fine-scale habitat use $(\psi)$ that appear to be linked to territorial behaviour. First, large areas of suitable habitat may not be used by male tigers, likely because these areas are not used by females. Second, in the populations we surveyed, only a relatively small proportion of sites was associated with the socially stable state 3 (use by female and only a single male). Lastly, the finding that a non-negligible amount of habitat is used by multiple males (regardless of female 
use) suggests potentially unstable social dynamics, in which male behavior may disrupt potential population growth. This could arise from infanticide and associated inter-sex aggression, as well as intra-sex competition to secure mates and increase harem sizes.

Our analyses also suggest that these inter-site variations in the probability of shared space use by male tigers may be attributed to, at least in part, by two inter-related factors: ASR and 310 degree of habitat connectivity or isolation. In the following sections, we (a) interpret our results 311 about linkages between ASR variation and probability of shared space use; (b) examine how 312 habitat connectivity and isolation may have some influence on ASR and population structure, and 313 thereby indirectly influence space use; (c) delve into potential demographic consequences of 314 shared space use (and ensuing intraspecific competition) on small populations of territorial 315 carnivores; and (d) elucidate the relevance of our study for conservation and management of tiger 316 populations in fragmented landscapes. First, we found that the considerable variation in co317 occurrence of tigers may be an artifact of adult sex ratios. A previous study noted that expansive 318 areas of habitat within some PAs (Dudhwa and Katerniaghat in our study) were associated with 319 low tiger use (Chanchani et al., 2016). Our results confirm that these sites had even or near-even 320 sex ratios (as many males as females) and were associated with higher probability of use at camera 321 trap locations (areas of the PA) with no use by male tigers, than a site with female-biased ASR. A 322 related finding was that sites with males per female, appear to be have lower likelihood of stable 323 space use (one male per female territory), and instead found some evidence for 'heaping' of 324 overlapping male territories in areas used by females, which potentially depresses population 325 growth rates. 
Second, we evaluate support for our prediction that the degree of overlapping space use in populations would be indirectly influenced by the degree of habitat connectivity or isolation. Our working hypothesis was that sites with poor connectivity would likely be associated with malebiased sex ratios. This prediction appears to be supported: Dudhwa and Katerniaghat both have

332 poorer habitat connectivity with other tiger occupied areas than Kishanpur, and were also 333 associated with even adult sex ratios, and associated patterns of fine-scale space use. A previous 334 study established that habitat connectivity influences tiger occupancy (Chanchani et al., 2016). 335 While we have not explicitly modeled the relationship between habitat connectivity and ASR in 336 this study, we think it may be a critical factor driving variation in adult sex ratios in our study area.

337 Our finding of similar probabilities of apparent survival for adult male and female tigers in the three study sites, lends support to the idea that habitat fragmentation, rather than variation in adult survival, may underlie skew in ASR and associated patterns of habitat use. While habitat

340 fragmentation has previously been associated with population declines and loss of genetic 341 heterozygosity (Mondol, et al. 2013), the 'indirect' impacts of fragmentation on population 342 demography and individual fitness have received less attention, even though is recognize that the omission of spatial structure can undermine analysis of population vulnerability (Gilpin, 1987). Third, we speculate that increased territorial overlap may have local effects on demography 345 and population structure. Specifically, we suggest that this will be on account of two factors. First, 346 male tigers in sites with male-biased ASR are likely to compete intensely for access to female 347 territories. Second, intensified competition between males may have deleterious effects on survival 348 of males, females and juveniles, with negative feedbacks on population growth. Reproductive 349 success, cub survival and population growth may be depressed for several reasons. Models of 350 equilibrium occupancy for territorial species predict that mate finding difficulties may lead to Allee 
351 effects (Stephens et al. 1999). For tigers, we are referring specifically to depensation-a decrease

352 in the size of the breeding population leading to reduced reproduction and lower population growth 353 rates (Lande, 1987).

354 We believe small tiger populations may exist below the ecological carrying capacity of 355 these sites as a consequence of a skewed ASR, among other factors .Recent population declines 356 populations in recent decades may have been accelerated by poor recruitment, survival and low 357 immigration of individuals, a result of poaching, habitat fragmentation and intraspecific 358 competition (Barlow et al., 2009; Carter et al., 2015). Further, Many tiger populations in habitat 359 fragments across the species range remain vulnerable to extinction because isolation reduces 360 genetic heterozygosity (Thatte et al., 2017). Extant habitats may only support small tiger 361 populations with elevated risk of patch -level extinction ( Noon and McKelvey, 1996; Thapa et 362 all., 2017).

We think it plausible that these and other factors have depressed tiger populations in some 364 PAs within our study area. estimated apparent survival probabilities for adult male and female 365 tigers were $10-15 \%$ lower in fragmented sites with male-biased ASR (Dudhwa and Katerniaght) 366 relative to larger and better connected habitats including Nagarhole in Southern India and Huai 367 Kha Khaeng Sanctuary in Thailand and PAs in Central and Western India (Duangchantrasiri et 368 al., 2016; Karanth et al., 2006; Majumder et al., 2017; Sadhu et al., 2017).

369 We attribute small population sizes and low survival rates primarily to poaching, in part, a 370 consequence of the proximity of our sites to the international border with Nepal (Chanchani et al., 371 2016). However, when poaching is combined with skewed, male-biased ASR, the increased 372 intraspecific competition and Allee effects have a synergistic negative effect on the populations 373 (Lande, 1998; Stephens and Sutherland, 1999). In the CTL, we speculate that male-biased ASR 
374 may result in reduced probabilities of encountering mates may be a consequence of both low 375 population density and increased competition among males to gain access to females (Rankin et 376 al., 2011; Wadekind, 2012). Difficulty in encountering potential mates may be compounded by

377 the occasional emigration of female tigers from protected areas. We documented two female tigers 378 raising cubs in sugarcane plantations away from primary habitats in PAs and Reserve Forests. Such 379 local movements, whether temporary or permanent, may be a response to the likelihood of 380 infanticide from a novel, but dominant male (Ebensperger, 1998; Singh et al., 2014; Swenson, 381 2003). Further mortality of sub-dominant (and often younger males) that arise from territorial 382 conflicts with established, dominant males may result in high rates of male mortality. One study in 383 Nepal ascribed 50\% of mortality of young male tigers due to intra-sexual aggression (Smith, 384 1993), even though the ASR in Chitwan National Park (Nepal) was 1:3. Finally, we note that 385 recovery may be a slow process in tiger populations with low adult survival (e.g., Katerniaghat and 386 Dudhwa), which are extinction-prone even if significant measures are implemented to increase 387 prey abundance Chapron et al (2008).

We are aware that overlapping space use by tigers, as inferred from camera trap data, is an 389 indirect measure of the potential for intra-specific conflict and does not provide probabilities or 390 frequencies of occurrence of actual conflict. Further, our results highlight that variation in ASR are 391 temporally dynamic, and that skewed ASR may be reversed by changing population vital rates 392 (related to Birth, Immigration, Death, Emigration. In our study, we recorded transitions in ASR 393 from male-biased to female-biased in one site, Katerniaghat WLS. Such switches may be triggered 394 by sex biased mortality or immigration/ emigration of a few individuals from or into small 395 populations (Robinson et al., 2008). We speculate that such reversals in ASR are more likely to 396 occur over shorter time intervals in sites with good habitat connectivity, than those with poor 
connectivity. While our sample size is small ( $\mathrm{n}=3$ sites), we are comparing these sites in the context of known variability (ASR, habitat connectivity) and based on our findings, there is generally consistent evidence supporting our hypothesis of possible influence of ASR and connectivity among our three study sites. We expect that this study will encourage others to look beyond population dynamics at behavioral and other endogenous factors that may profoundly influence tiger space and demography, which will help add support to or refine ideas brought up in this manuscript.

\subsection{Conservation and Management Implications}

The maintenance of viable carnivore metapopulations requires that functional habitat connectivity be maintained and that all available habitats, regardless of PA designation, be effectively protected (Wikramanayake et al., 2011) In many areas across the extant range of large carnivores, the lack of effective protection from poaching has led to large habitat tracts that support very low tiger densities (Hilborn et al., 2006; Liberg et al., 2012). For example, in the Terai, extensive tracts of suitable habitat in Nepal, only 1-2 kilometers away from the northern boundary of DNP, face high hunting pressure of both tigers and their prey. As a result, they rarely sustain breeding females whose offspring may disperse into Dudhwa NP's productive riparian habitats (Wikramanayake et al., 2010; Chanchani et al., 2014(b)). However, our finding of malebiased ASR in DNP, despite lower male survival rates of resident males, suggests that males may occasionally immigrate into the park from surrounding areas, as is observed in many large carnivores (Sweanor et al., 2000).

However, rapid land use change is severely degrading wildlife corridors in human dominated landscapes, and may severely limit the movement of large mammals through the matrix (Joshi et al., 2016). The maintenance and restoration of vital wildlife corridors often have little 
420 political support, especially if they involve land acquisition or displacement of people. In the

421 absence of formal corridors, we are increasingly documenting the use of the surrounding

422 agricultural matrix by large carnivores (Athreya et al., 2013; Joshi et al., 2013). If policies can be

423 developed to minimize human-wildlife conflict and increase human tolerance of tigers (and prey)

424 in the agricultural matrix, it may be possible to compensate to some extent for inadequate extent of

425 protected area and lack of law enforcement (Gosling, 2003). Our study suggests that in the CTL

426 there may be less than the assumed three adult females per male in many tiger populations, even in

427 areas with good habitat connectivity. Similar skews in sex ratios may also exist among other large

428 carnivore species (Palomares et al., 2012). The persistence of small populations of territorial

429 species requires protecting and increasing prey populations and maintaining high adult survival

430 rates (Chapron et al., 2008; Karanth and Stith, 1999). The success of these and other conservation

431 measures requires not only upon political will, but also societal involvement in, and support for

432 conservation (Oldekop et al., 2015; Rastogi et al., 2012). Finally, our study underscores that

433 poaching and habitat fragmentation often result in male-biased ASR with the potential to

434 accelerate rates of population decline. Managers must therefore routinely monitor sex-ratios,

435 reproduction and survival, in addition to population size.

436 Finally, for carnivore populations with severely skewed ASR and low abundance,

437 recovery and persistence may well depend on the timely implementation of mitigation measures

438 such as the supplementation of breeding-age individuals to compensate for skewed sex-ratios

439 (Lambertucci et al., 2013; Reddy et al., 2016). With population declines in various areas, this is

440 increasingly being viewed as an essential and viable strategy to achieve tiger population recovery

441 across the species range ( Sankar et al., 2010; Gray et al., 2017; Kolipaka et al., 2017; Harihar et

442 al., 2018), 


\section{Acknowledgements:}

444 The Uttar Pradesh Forest Department granted necessary permits and provided logistic support.

445 Fieldwork was facilitated by funding from the U.S Fish and Wildlife Service's Rhinoceros and

446 Tiger Conservation Award, WWF-India, and WWF's Kathryn Fuller Science for Nature

447 Fellowship (awarded to PC). We also gratefully acknowledge collaboration from K Ramesh and

448 B. Pandav at the Wildlife Institute of India, and M.Gupta, D. Ghose, J. Borah and J. Vattakaven

449 at WWF-India. A. Bista, S. Nair, R. Warrier, R. Ravi, M. D'Almeida, R Sharma and S.S Bisht

450 contributed spiritedly to fieldwork. N.T Hobbs, J. Tack, L.L Bailey and K. Crooks provided

451 helpful advice on analysis and edited this manuscript. Finally, this manuscript was considerably

452 strengthened based on the feedback of two anonymous reviewers.

453 


\section{References}

Athreya, V., Odden, M., Linnell, J.D.C., Krishnaswamy, J., Karanth, U., 2013. Big cats in our backyards: persistence of large carnivores in a human dominated landscape in India. PLoS One 8, e57872. doi:10.1371/journal.pone.0057872

Barber-Meyer, S.M., Jnawali, S.R., Karki, J.B., Khanal, P., Lohani, S., Long, B., Mackenzie, D.I., Pandav, B., Pradhan, N.M.B., Shrestha, R., Subedi, N., Thapa, G., Thapa, K., Wikramanayake, E., 2013. Influence of prey depletion and human disturbance on tiger occupancy in Nepal. J. Zool. 289, 10-18. doi:10.1111/j.1469-7998.2012.00956.x

Barlow, A.C.D., McDougal, C., Smith, J.L.D., Gurung, B., Bhatta, S.R., Kumal, S., Mahato, B., Tamang, D.B., 2009. Temporal Variation in Tiger (Panthera tigris) Populations and its Implications for Monitoring. J. Mammal. 90, 472-478. doi.org/10.1644/07-MAMM-A$\underline{415.1}$.

Barrientos, R., 2015. Adult sex-ratio distortion in the native European polecat is related to the expansion of the invasive American mink. Biol. Conserv. 186, $28-34$. doi:10.1016/j.biocon.2015.02.030

Carter, N., Levin, S., Barlow, A., Grimm, V., 2015. Modeling tiger population and territory dynamics using an agent-based approach. Ecol. Modell. 312, 347-362. doi:10.1016/j.ecolmodel.2015.06.008

Caswell, H., 2001. Matrix populaion models: construction, analysis and interpretation. Sinauer Associates.

Chanchani, P., Bista, A., Warrier, R.A., Nair, S., Sharma, R., Hassan, D., Gupta, M., 2014a. Status and conservation of tigers and their prey in the Uttar Pradesh terai. WWF-India, New Delhi. 
Chanchani, P., Lamichhane, B.R., Malla, S., Maurya, K., Bista, A., Warrier, R., Nair, S., Almeida, M., Ravi, R., Sharma, R., Dhakal, M., Yadav, S.P., Thapa, M., Jnawali, S.R., Pradhan, N.B.., Subedi, N., Thapa, G., Yadav, H., Jhala, Y. V., Qureshi, Q., Vattakaven, J., Borah, J., 2014b. Tigers of the Transboundary Terai Arc Landscape: Status, distribution and movement in the Terai of India and Nepal. National Tiger Conservation Authority of India, New Delhi and Departmenet of National Parks and Widlife Conservation, Kathmandu.

Chanchani, P., Noon, B.R., Bailey, L.L., Warrier, R.A., 2016. Conserving Tigers in working landscapes. Conserv. Biol. 30, 649-660. doi:10.1111/cobi.12633

Chanchani, P., 2016. Spatial ecology and conservation of tigers and their prey in the central terai landscape, India. Colorado State University, Fort Collins.

Chapron, G., Miquelle, D.G., Lambert, A., Goodrich, J.M., Legendre, S., Clobert, J., 2008. The impact on tigers of poaching versus prey depletion. J. Appl. Ecol. 45, 1667-1674. doi:10.1111/j.1365-2664.2008.01538.x

Clutton-Brock, T.H., Coulson, T.., Milner-Gulland, E.J., Thomson, D., Armstrong, H.., 2002. Sex differences in emigration and mortality affect optimal management of deer populations. Nature 415, 633-637. doi:10.1038/415633a

Duangchantrasiri, S., Umponjan, M., Simcharoen, S., Pattanavibool, A., Chaiwattana, S., Maneerat, S., Kumar, N.S., Jathanna, D., Srivathsa, A., Karanth, K.U., 2016. Dynamics of a low-density tiger population in Southeast Asia in the context of improved law enforcement. Conserv. Biol. 30, 639-648. doi:10.1111/cobi.12655

Ebensperger, L.A., 1998. Strategies and counterstragies to infanticide in mammals. Biol. Rev. $73,321-346$.

Gelman, A., Hill, J., 2007. Data Analysis Using Regression and Multilevel/Hierarchical Models. 
Cambridge University Press, New York.

Gilpin, E., 1987. Spatial structure and population vulnerability, in: Soulé, M.E. (Ed.), Viable Populations for Conservation. Cambridge University Press, Cambridge, UK.

Goodrich, J.M., Kerley, L.L., Smirnov, E.N., Miquelle, D.G., McDonald, L., Quigley, H.B., Hornocker, M.G., McDonald, T., 2008. Survival rates and causes of mortality of Amur tigers on and near the Sikhote-Alin Biosphere Zapovednik. J. Zool. 276, 323-329. doi:10.1111/j.1469-7998.2008.00458.x

Gosling, L.M., 2003. Adaptive behavior and population viability, in: Festa-Bianchet, M., Apollonio, M. (Eds.), Animal Behavior and Wildlife Conservation. Island Press, Washington D.C., pp. 13-30.

Gray, T.N.E., Crouthers, R., Ramesh, K., Vattakaven, J., Borah, J., Pasha, M.K.S., Lim, T., Phan, C., Singh, R., Long, B., Chapman, S., Keo, O., Baltzer, M., 2017. A framework for assessing readiness for tiger Panthera tigris reintroduction : a case study from eastern. Biodivers. Conserv. doi:10.1007/s10531-017-1365-1

Grayson, K.L., Mitchell, N.J., Monks, J.M., Keall, S.N., Wilson, J.N., Nelson, N.J., 2014. Sex Ratio Bias and Extinction Risk in an Isolated Population of Tuatara (Sphenodon punctatus). PLoS One 9, e94214. doi:10.1371/journal.pone.0094214

Haridas, C.V., Eager, E.A., Rebarber, R., Tenhumberg, B., 2014. Frequency-dependent population dynamics: Effect of sex ratio and mating system on the elasticity of population growth rate. Theor. Popul. Biol. 97, 49-56. doi:10.1016/j.tpb.2014.08.003

Harihar, A., Ghosh-Harihar, M., Macmillan, D.C., 2018. Losing time for the tiger Panthera tigris: Delayed action puts a globally threatened species at risk of local extinction. Oryx 52, 78 88. doi:10.1017/S0030605317001156 
Harihar, A., Pandav, B., 2012. Influence of connectivity, wild prey and disturbance on occupancy of tigers in the human-dominated western Terai Arc landscape. PLoS One 7, 110. doi:10.1371/journal.pone.0040105

Hilborn, R., Arcese, P., Borner, M., Hando, J., Hopcraft, G., Loibooki, M., Mduma, S., Sinclair, A.R.E., 2006. Effective enforcement in a conservation area. Science 314, 1266. doi:10.1126/science. 1132780

Hobbs, T.N., Hooten, M.B., 2015. Bayesian models: A statistical primer for ecologists. Princeton University Press, Princeton, NJ.

Horev, A., Yosef, R., Tryjanowski, P., Ovadia, O., 2012. Consequences of variation in male harem size to population persistence: Modeling poaching and extinction risk of Bengal tigers (Panthera tigris). Biol. Conserv. 147, 22-31. doi:10.1016/j.biocon.2012.01.012

Hrdy, S.B., 1979. Infanticide among animals: A review, classification, and examination of the implications for the reproductive strategies of females. Ethol. Sociobiol. 1, 13-40. doi:10.1016/0162-3095(79)90004-9

Jhala, Y. V., Qureshi, Q., Gopal, R., (eds.) 2015. Status of tigers, copredators and their prey in India, 2014. Dehradun, India. National Tiger Conservation Authority of India, New Delhi. Jhala, Y. V., Qureshi, Q., Gopal, Sinha, P.R., 2011. Status of tigers, co-predators and prey in India, 2010. doi:TR 2011/003 pp-302. National Tiger Conservation Authority of India, New Delhi.

Johnsingh, A.J.T., Ramesh, K., Qureshi, Q., David, A., Goyal, S.P., Rawat, G.S., Kanagaraj, R., Prasad, S., 2004. Conservation Status of Tiger and Associated Species in the Terai Arc Landscape, India. Wildlife Institute of India,Dehradun.

Joshi, A., Vaidyanathan, S., Mondol, S., Edgaonkar, A., Ramakrishnan, U., 2013. Connectivity 
of Tiger (Panthera tigris) Populations in the Human-Influenced Forest Mosaic of Central India. PLoS One 8, e77980. doi:10.1371/journal.pone.0077980

Joshi, A.R., Dinerstein, E., Wikramanayake, E., Anderson, M.L., Olson, D., Jones, B.S., Seidensticker, J., Lumpkin, S., Hansen, M.C., Sizer, N.C., Davis, C.L., Palminteri, S., Hahn, N.R., 2016. Tracking changes and preventing loss in critical tiger habitat. Sci. Adv. 2, e1501675-e1501675. doi:10.1126/sciadv.1501675

Kanagaraj, R., Wiegand, T., Kramer-Schadt, S., Goyal, S.P., 2013. Using individual-based movement models to assess inter-patch connectivity for large carnivores in fragmented landscapes. Biol. Conserv. 167, 298-309. doi:10.1016/j.biocon.2013.08.030

Karanth, K.U., Gopalaswamy, A.M., Kumar, N.S., Vaidyanathan, S., Nichols, J.D., Mackenzie, D.I., 2011. Monitoring carnivore populations at the landscape scale: Occupancy modelling of tigers from sign surveys. J. Appl. Ecol. 48, 1048-1056. doi:10.1111/j.13652664.2011.02002.x

Karanth, K.U., Nichols, J.D., Kumar, N.S., Hines, J.E., 2006. Assessing tiger population dynamics using photographic capture-recapture sampling. Ecology 87, 2925-2937. doi:10.1890/0012-9658(2006)87[2925:ATPDUP]2.0.CO;2

Karanth, K.U., Stith, B.M., 1999. "Prey depletion as a critical determinant of tiger population viability, in: Riding the Tiger: Tiger Conservation in Human-Dominated Landscapes. Cambridge University Press, Cambridge.

Karanth, U.K., Nichols, J.D., Kumar, N.S., 2002. Monitoring tigers and their prey: a manual for researchers, managers, and conservationists in tropical Asia, in: Karanth, U.K., Nichols, J.D. (Eds.), . Centre for Wildlife Studies., Bangalore.

Kery, M., Schaub, M., 2012. Bayesian Population Analysis using WinBUGS: A hierarchical 
perspective. Academic Press, Waltham, MA.

Kolipaka, S.S., Persoon, G.A., Iongh, H.H. De, 2017. New insights into the factors influencing movements and spatial distribution of reintroduced Bengal tigers ( Panthera tigris tigris) in the human-dominated buffer zone of Panna Tiger Reserve , India. doi:10.1515/mammalia2016-0126

Lambertucci, S.A., Carrete, M., Speziale, K.L., Hiraldo, F., Donázar, J.A., 2013. Population Sex Ratios: Another Consideration in the Reintroduction - Reinforcement Debate? PLoS One 8, 1-7. doi:10.1371/journal.pone.0075821

Lande, R., 1998. Anthropogenic, ecological and genetic factors in extinction and conservation. Res. Popul. Ecol. (Kyoto). 40, 259-269. doi:10.1007/BF02763457

Lande, R., 1987. Extinction Thresholds in Demographic Models of Territorial Populations. Am. Nat. 130, 624-635. doi.org/10.1086/284734

Le Galliard, J.F., Fitze, P.S., Ferrière, R., Clobert, J., 2005. Sex ratio bias, male aggression, and population collapse in lizards. ings Natl. Acad. Sci. United States Am. 102, 18231-18236. doi.org/10.1073/pnas.0505172102

Lebreton, J.-D., Burnham, K.P., Clobert, J., Anderson, D.R., 1992. Modeling Survival and Testing Biological Hypotheses Using Marked Animals : A Unified Approach with Case Studies. Ecol. Monogr. 62, 67-118.doi.org/10.2307/2937171

Liberg, O., Chapron, G., Wabakken, P., Pedersen, H.C., Hobbs, N.T., Sand, H., 2012. Shoot, shovel and shut up: cryptic poaching slows restoration of a large carnivore in Europe. Proceedings. Biol. Sci. 279, 910-5. doi:10.1098/rspb.2011.1275

López-Sepulcre, A., Norris, K., Kokko, H., 2009. Reproductive conflict delays the recovery of an endangered social species. J. Anim. Ecol. 78, 219-225. doi:10.1111/j.1365- 
2656.2008.01475.x

Majumder, A., Qureshi, Q., Sankar, K., Kumar, A., 2017. Long-term monitoring of a Bengal tiger (Panthera tigris tigris) population in a human-dominated landscape of Central India. Eur. J. Wildl. Res. 63, 1-11. doi:10.1007/s10344-016-1070-5

Mondol, S., Bruford, M.W., Ramakrishnan, U., 2013. Demographic loss, genetic structure and the conservation implications for Indian tigers. Proc. Biol. Sci. 280, 20130496. doi:10.1098/rspb.2013.0496

Nichols, J.D., Hines, J.E., Mackenzie, D.I., Seamans, M.E., Gutierrez, R.J., 2007. Occupancy estimation and modeling with multiple states and state uncertainty. Ecology 88, 1395-1400. doi:10.1890/06-1474

Noon, B.R., McKelvey, K.S., 1996. A common framework for conservation planning: linking individual and metappopulation models, in: McCullough, D.R. (Ed.), Metapopulations and Wildlife Conservation. Island Press, Washington D.C.

O’Connell, A.F., Bailey, L.L., 2011. Inference for occupancy and occupancy dynamics, in: O’Connell, A.F., Nichols, J.D., Karanth, U.K. (Eds.), Camera Traps in Animal Ecology: Methods and Analyses. Springer, New York, pp. 191-206.

Oldekop, J.A., Holmes, G., Harris, W.E., Evans, K.L., 2015. A global assessment of the social and conservation outcomes of protected areas. Conserv. Biol. 30, 133-141. doi:10.1111/cobi.12568

Palomares, F., Roques, S., Chavez, C., Silveira, L., Keller, C., Sollmann, R., do Prado, D.M., Torres, P.C., Adrados, B., Godoy, J.A., Jacomo, de A.A.T., Torres, N.M., Furtado, M.M., Lopez-Bao, J.V., 2012. High Proportion of Male Faeces in Jaguar Populations. PLoS One 7 e52923. doi:10.1371/journal.pone.0052923 
Persson, J., Willebrand, T., Landa, A., Andersen, R., Segerström, P., 2003. The role of intraspecific predation in the survival of juvenile wolverines Gulo gulo. Wildlife Biol. 9, 21 $-28 \ldots \ldots . . . \ldots \ldots . . . .$.

Plummer, M., 2003. JAGS: A program for analysis of Bayesian graphical models using Gibbs sampling.

Polis, G.A., 1981. The evolution and dynamics of intraspecific predation. Annu. Rev. Ecol. Syst. 12, 225-251. doi.org/10.1146/annurev.es.12.110181.001301

Rankin, D.J., Dieckmann, U., Kokko, H., 2011. Sexual Conflict and the Tragedy of the Commons. Am. Nat. 177, 780-791. doi:10.1086/659947

Rastogi, A., Hickey, G.M., Badola, R., Hussain, S.A., 2012. Saving the superstar: A review of the social factors affecting tiger conservation in India. J. Environ. Manage. 113, 328-340. doi:10.1016/j.jenvman.2012.10.003

Reddy, A., Ramesh, K., Shekhar Sarkar, M., Srivastava, A., Bhavanishankar, M., Shivaji, S., 2016. Significance of mate selection and adult sex ratio in tiger reintroduction/reinforcement programs. J. Zool. 299, 132-141. doi:10.1111/jzo.12331

Ripple, W.J., Estes, J.A., Beschta, R.L., Wilmers, C.C., Ritchie, E.G., Hebblewhite, M., Berger, J., Elmhagen, B., Letnic, M., Nelson, M.P., Schmitz, O.J., Smith, D.W., Wallach, A.D., Wirsing, A.J., 2014. Status and ecological effects of the world's largest carnivores. Science 343, 1241484. doi:10.1126/science. 1241484

Robinson, H.S., Wielgus, R.B., Cooley, H.S., Cooley, S.W., 2008. Sink Populations in Carnivore Management : Cougar Demography and Immigration in a Hunted Population. Ecol. Appl. 18, 1028-1037. doi:10.1890/07-0352.1

Royle, J.A., Dorazio, R.M., 2008. Hierarchical Modeling and Inference in Ecology. Academic 
Press, London.

Sadhu, A., Jayam, P.P.C., Qureshi, Q., Shekhawat, R.S., Sharma, S., Jhala, Y.V., 2017.

Demography of a small, isolated tiger (Panthera tigris tigris) population in a semi-arid region of western India. BMC Zool. 2, 16. doi:10.1186/s40850-017-0025-y

Sankar, K., Qureshi, Q., Nigam, P., Malik, P.K., Sinha, P.R., Mehrotra, R.N., Gopal, R., Mondal, K., Gupta, S., 2010. Monitoring of reintroduced tigers in Sariska Tiger Reserve , Western India : preliminary findings on home range, prey selection and food habits $3,301-318$. Tropical Conservation Science. 3, 301-318. doi.org/10.1177/194008291000300305

Singh, R., Nigam, P., Qureshi, Q., Sankar, K., Krausman, P.R., Goyal, S.P., 2014. Strategy of female tigers to avoid infanticide. Curr. Sci. 107, 1595-1597. .....

Smith, J., McDougal, C., Miquelle, D.G., 1989. Scent marking in free ranging tigers, Panthera tigris. Anim. Behav. 37, 1-10. doi.org/10.1016/0003-3472(89)90001-8

Smith, J.L.D., 1993. The Role of Dispersal in Structuring the Chitwan Tiger Population. Behaviour 124, 165-195. doi:10.1163/156853993X00560

Smith, J.L.D., McDougal, C., 1991. The contribution of variance in lifetime reproduction to effective population size in tigers. Conserv. Biol. 5, 484-490. doi:10.1111/j.15231739.1991.tb00355.x

Stephens, P.A., Sutherland, W.J., 1999. Consequences of the Allee effect for behaviour, ecology and conservation. Trends Ecol. Evol. 14, 401-405. doi:10.1016/S0169-5347(99)01684-5

Strahorn, E.A., 2009. An Environmental History of Postcolonial North India: The Himalayan Tarai in Uttar Pradesh and Uttaranchal. Peter Lang, New York.

Sunarto, S., Kelly, M.J., Parakkasi, K., Klenzendorf, S., Septayuda, E., Kurniawan, H., 2012. Tigers need cover: Multi-scale occupancy study of the big cat in Sumatran forest and 
plantation landscapes. PLoS One 7, e30859. doi:10.1371/journal.pone.0030859

Sunquist, M.E., 1981. The social organization of tigers (Panthera tigris) in Royal Chitwan National Park, Nepal. Smithson. Contrib. to Zool. 336, 1-98.

Sweanor, L.L., Logan, K.A., Hornocker, M.G., 2000. Cougar Dispersal Patterns, Metapopulation Dynamics, and Conservation. Conserv. Biol. 14, 798-808. doi:10.1046/j.15231739.2000.99079.x

Swenson, J.E., 2003. Implications of sexually selected infanticide for the hunting of large carnivores, in: Festa-Bianchet, M., Apollonio, M. (Eds.), Animal Behavior and Wildlife Conservation. Island Press, Washington D.C.

Székely, T., Weissing, F.., Komdeur, J., 2014. Adult sex ratio variation: implications for breeding system evolution. . J. Evol. Biol. 27, 1500-1512. doi.org/10.1111/jeb.12415

Thapa, K., Wikramanayake, E., Malla, S., Acharya, K.P., Lamichhane, B.R., Subedi, N., Pokharel, C.P., Thapa, G.J., Dhakal, M., Bista, A. and Borah, J., 2017. Tigers in the Terai: Strong evidence for meta-population dynamics contributing to tiger recovery and conservation in the Terai Arc Landscape. PloS one, 12, p.e0177548.

Thatte, P., Joshi, A., Vaidyanathan, S., Landguth, E. and Ramakrishnan, U., 2018. Maintaining tiger connectivity and minimizing extinction into the next century: Insights from landscape genetics and spatially-explicit simulations. Biol. Conserv., 218,.181-191. doi.org/10.1016/j.biocon.2017.12.022

Veran, S., Beissinger, S.., 2009. Demographic origins of skewed operational and adult sex ratios: perturbation analyses of two-sex models. Ecol. Lett. 129-143. doi.org/10.1111/j.1461$\underline{0248.2008 .01268 . x}$ 
Wadekind, C., 2012. Managing population sex ratios in conservation practie: how and why?, in: Povilitis, T. (Ed.), Topics in Conservation Biology. InTech, Rijeka, pp. 81-96.

Wikramanayake, E., Dinerstein, E., Seidensticker, J., Lumpkin, S., Pandav, B., Shrestha, M., Mishra, H., Ballou, J., Johnsingh, A.J.T., Chestin, I., Sunarto, S., Thinley, P., Thapa, K., Jiang, G., Elagupillay, S., Kafley, H., Pradhan, N.M.B., Jigme, K., Teak, S., Cutter, P., Aziz, M.A., Than, U., 2011. A landscape-based conservation strategy to double the wild tiger population. Conserv. Lett. 4, 219-227. doi:10.1111/j.1755-263X.2010.00162.x

Wikramanayake, E., McKnight, M., Dinerstein, E., Joshi, A., Gurung, B., Smith, D., 2004. Designing a conservation landscape for tigers in human-dominated environments. Conserv. Biol. 18, 839-844. doi:10.1111/j.1523-1739.2004.00145.x

Wikramanayake, E., Manandhar, A., Bajimaya, S., Nepal, S., Thapa, G. and Thapa, K., 2010. The Terai Arc Landscape: A tiger conservation success story in a human-dominated landscape. In Nyhus, P.J and Tislon, R (eds) Tigers of the World (Second Edition) (pp. 163173). 
Figures

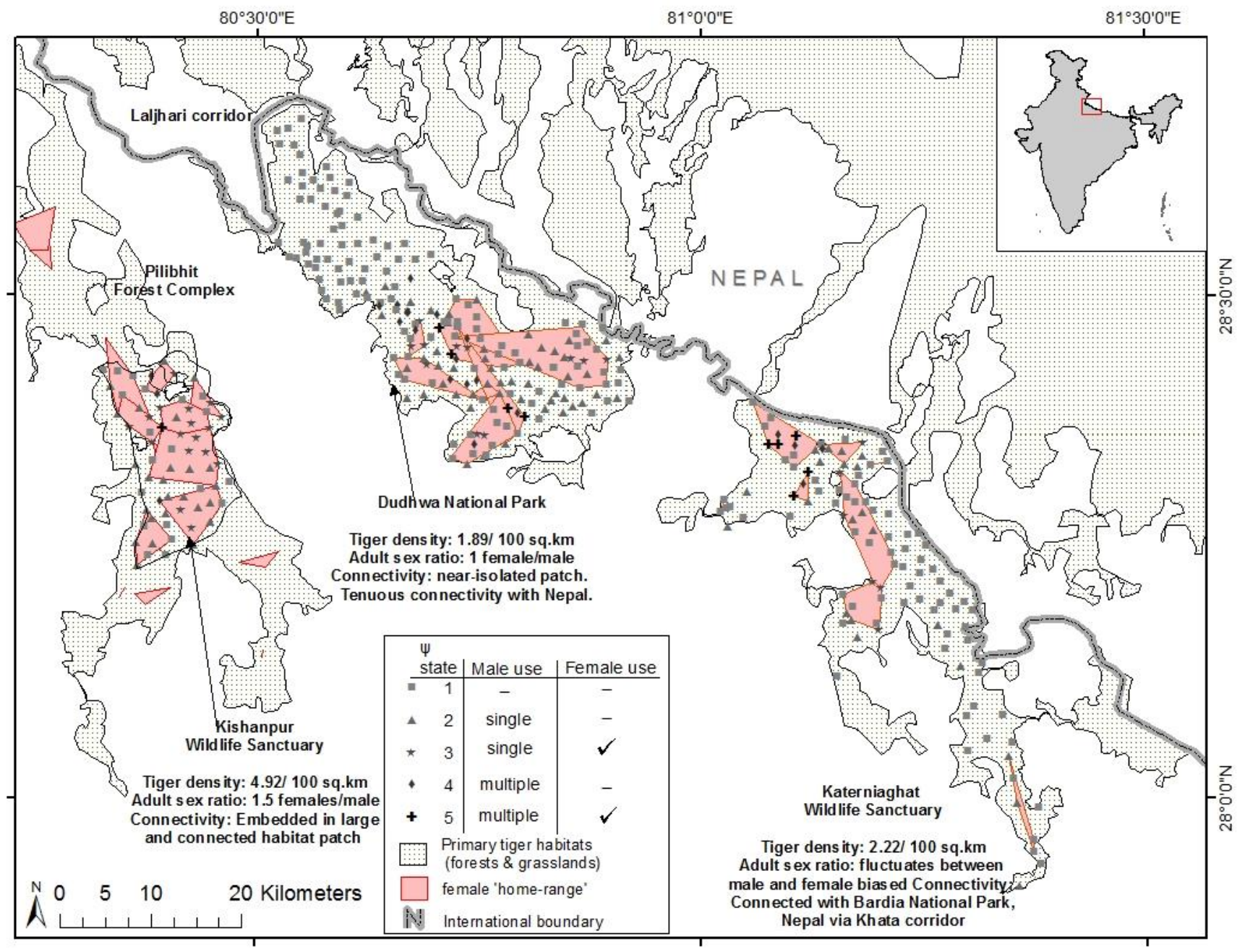

Figure 1. Map of the Central Terai Landscape depicting female home range locations, and statewise 'photo-capture locations of male tigers (in 2013). The approximate 'home ranges' of females tigers (defined by minimum convex polygons around capture locations) are delineated in beige. 


\section{Figure 2}

Ecological Process:

$z_{i} \sim \operatorname{Categorical}\left(\Omega_{i}\right)$

$\Omega_{i}=\left[\begin{array}{c}1-\psi-\psi^{\prime} \\ \psi \times(1-f) \\ \psi \times f \\ \psi^{\prime} \times(1-f) \\ \psi \times^{\prime}(f)\end{array}\right] \begin{gathered}\text { State 1 } \\ \text { State 2 } \\ \text { State 3 } \\ \text { State 5 }\end{gathered}$

Observation Process:

$y_{i, j} \mid \mathrm{z}_{i} \sim \operatorname{Categorical}\left(\theta\left[\mathrm{z}_{i}(s),{ }_{j}\right]\right)$

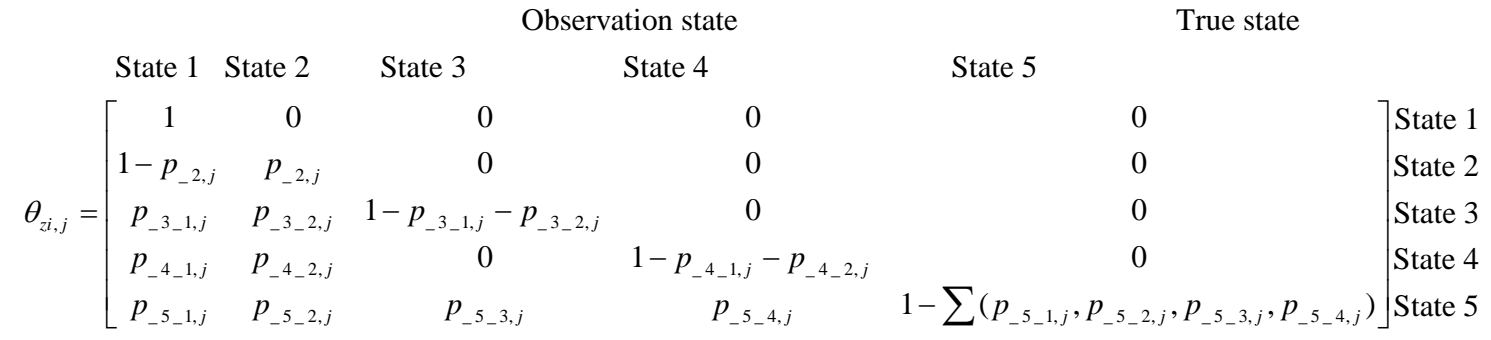

Occupancy state priors:

lpsi $\sim \operatorname{Normal}(0,2), \psi^{\prime} \sim \operatorname{Normal}(0,2), f \sim \operatorname{Beta}(1,1)$

To constrain the parameters $\psi$ and $\psi^{\prime}$ of the state matrix such that theiur sum was $\leq 1$, we used a

logit transformation.

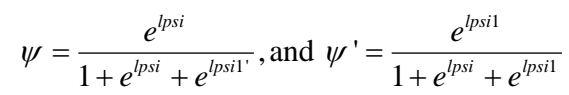

Joint posterior distribution:

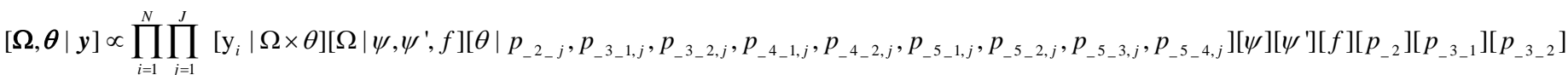

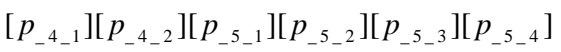


Figure 2. Bayesian, multi state occupancy model used to test hypothesis about habitat use and intra-specific completion among male tigers. The five true (latent) habitat use states are State 1: no male use; State 2: location use by single male tiger and no female use; State 3: habitat use by a single male tiger and female use; State 4: habitat use by multiple male tigers and no female use; State 5: habitat use by multiple male tigers, and female use. The observation matrix $(\theta)$ details the observation process associated the detection of tigers in each of the five habitat use states at site (i) and sampling occasion $(j)$. The diagonal elements are the probabilities of correct classification and the all off-diagonals are probabilities of mis-classification of a state. The probabilities in each row of the matrix sum to 1 . All $\mathrm{p}_{\mathrm{ij}}$ are vectors of detection parameters that vary by time. 


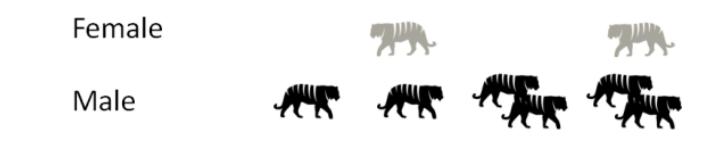

a
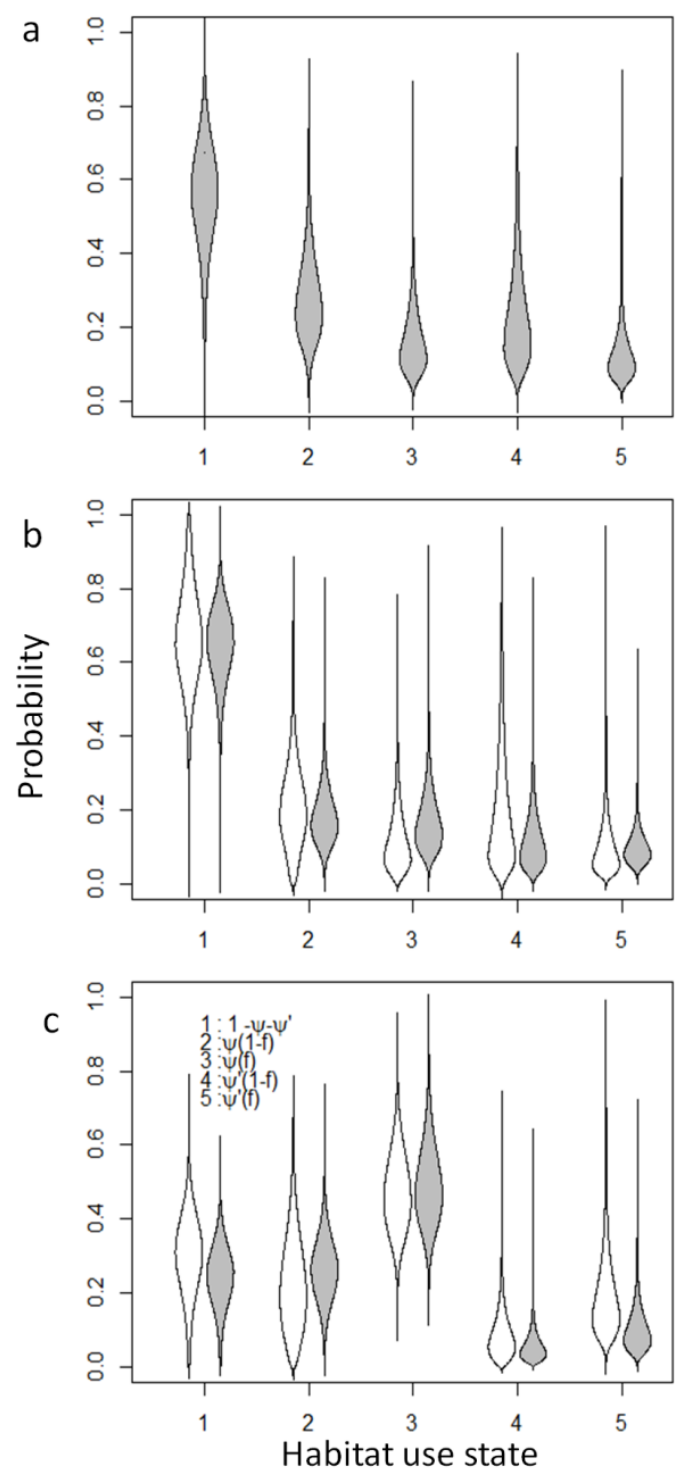

Figure 3: Posterior distributions for parameters linked to the five habitat use states for three PAs in DTR (a) Dudhwa NP,(b) Katerniaghat WLS and (c) Kishanpur WLS) over the two study-years (white: 2012 and grey: 2013). These PAs span gradients of habitat connectivity and ASR (malebiased to female-biased). The width of the strip in these plots is proportional to the density. Tiger silhouettes at the top of the figure indicate habitat use states, i.e., use by 0,1 or $>1$ males, with ( 1 or more) and without female use. 


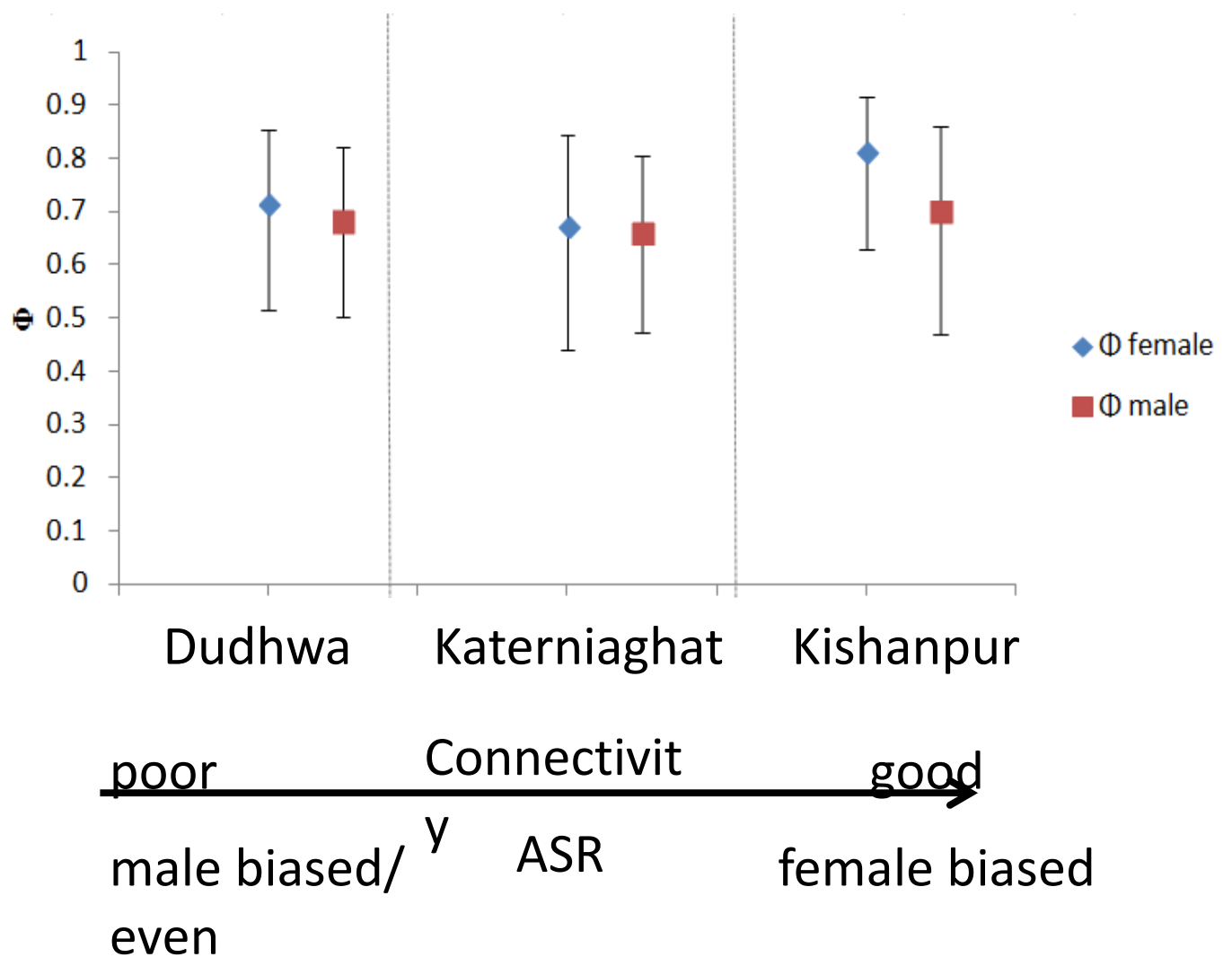


Figure 4. Model averaged estimates of apparent survival probability of male and female tigers in DTR's three protected areas over a 4-year period (2010-2014). 


\section{Tables}

Table 1. Five occupancy states for male tigers and associated patterns of habitat-use, and specific predictions in relation to ASR.

\begin{tabular}{|c|c|c|c|c|}
\hline \multicolumn{2}{|c|}{ Occupancy state for male tigers } & \multicolumn{2}{|c|}{$\begin{array}{l}\text { Probability of fine-scale } \\
\text { habitat use by male tigers }\end{array}$} & \multirow[t]{2}{*}{ Specific hypotheses } \\
\hline & & Category 1 & Category 2 & \\
\hline $\begin{array}{l}\text { State } 1 \\
\left(1-\Psi-\Psi^{\prime}\right)\end{array}$ & No male use & $\operatorname{High}(++)$ & Low (- -) & $\begin{array}{l}\text { High probability that large areas of available habitat may go unused } \\
\text { by male tigers in sites with male-biased ASR, because males hone in } \\
\text { on female territories. }\end{array}$ \\
\hline $\begin{array}{l}\text { State } 2 \\
\Psi(1-f)\end{array}$ & $\begin{array}{l}\text { Use by single male } \\
\text { tiger and no female } \\
\text { use }\end{array}$ & High (+) & Low (-) & $\begin{array}{l}\text { A few dominant males are expected to secure and restrict access to } \\
\text { females in sites with male-biased ASR. Thus, higher likelihood of } \\
\text { male tiger use outside of female territories is expected. }\end{array}$ \\
\hline $\begin{array}{l}\text { State } 3 \\
\Psi(f)\end{array}$ & $\begin{array}{l}\text { Use by single male } \\
\text { tiger and female use }\end{array}$ & Low (-) & High (+) & $\begin{array}{l}\text { In sites with male-biased ASR, males with compete fiercely for } \\
\text { access to females. In sites with female-biased ASR, there is a higher } \\
\text { probability that every male tiger in the population will have access to } \\
\text { one or more female(s). }\end{array}$ \\
\hline $\begin{array}{l}\text { State } 4 \\
\Psi^{\prime}(1-f)\end{array}$ & $\begin{array}{l}\text { Use by multiple } \\
\text { male tigers and no } \\
\text { female use }\end{array}$ & $\operatorname{High}(++)$ & Low (-) & $\begin{array}{l}\text { High probability of shared habitat use by multiple male tigers in sites } \\
\text { with male-biased ASR because of increased intraspecific competition } \\
\text { for mates. Shared use of sites expected in the vicinity of female } \\
\text { home-range boundaries. }\end{array}$ \\
\hline $\begin{array}{l}\text { State } 5 \\
\Psi^{\prime}(\mathrm{f})\end{array}$ & $\begin{array}{l}\text { Use by multiple } \\
\text { male tigers and } \\
\text { female use }\end{array}$ & High (+) & Low (-) & $\begin{array}{l}\text { High probability of shared habitat use by multiple male tigers in sites } \\
\text { with male-biased ASR because of increased intraspecific competition } \\
\text { for mates. Territorial behavior may reduce shared use of locations, } \\
\text { relative to sites with no female use. }\end{array}$ \\
\hline
\end{tabular}

Footnotes:

Category 1 sites (i.e. Dudhwa National Park) have the following characteristics: poor habitat connectivity, male-biased/ even ASR and lower adult survival rates (expected)

Category 2 sites (i.e. Kishanpur Wildlife Sanctuary) have the following characteristics: good habitat connectivity, female-biased ASR and higher adult survival rates. 
Table 2. Details of camera trap effort in DTR's three protected areas. $p_{m i x}$ is the estimated proportion of males in the population based on a spatially-explicit, capture-recapture model. DNP and Katerniaghat have male-biased/even sex ratios and relatively poor habitat connectivity. Kishanpur has female-biased sex ratios and good habitat connectivity.

\begin{tabular}{|c|c|c|c|c|c|c|c|c|c|c|c|}
\hline Site & Year & $\begin{array}{l}\text { No. } \\
\text { of } \\
\text { Came } \\
\text { ras }\end{array}$ & $\begin{array}{c}\text { Effort } \\
\text { (trap } \\
\text { nights) }\end{array}$ & $\begin{array}{c}\text { No. of } \\
\text { unique } \\
\text { individuals } \\
\text { detected }\end{array}$ & $\begin{array}{c}\text { Total } \\
\text { captures }\end{array}$ & $\begin{array}{l}\text { No. of } \\
\text { females }\end{array}$ & $\begin{array}{l}\text { No. of } \\
\text { female } \\
\text { captures }\end{array}$ & $\begin{array}{l}\text { No. of } \\
\text { males }\end{array}$ & $\begin{array}{c}\text { No. of male } \\
\text { captures }\end{array}$ & $\begin{array}{c}\text { Males/ } \\
\text { female } \\
\text { a }\end{array}$ & $\begin{array}{c}\text { Estimated } \\
\text { tiger } \\
\text { density/100k } \\
\mathrm{m}^{2 \mathrm{~b}} \\
\end{array}$ \\
\hline DNP & 2012 & 159 & 2626 & 14 & 126 & 5 & 42 & 9 & 84 & 1.80 & $2.05(0.38)$ \\
\hline $\begin{array}{l}\text { DNP } \\
\text { Katerniagha }\end{array}$ & 2013 & 202 & 4861 & 14 & 274 & 7 & 92 & 7 & 182 & 1.00 & $1.89(0.34)$ \\
\hline Katerniagha & 2012 & 82 & 2190 & 18 & 88 & 7 & 35 & 11 & 53 & 1.57 & $4.72(0.92)$ \\
\hline $\mathrm{t}$ & 2013 & 111 & 3663 & 17 & 207 & 11 & 106 & 7 & 101 & 0.636 & $2.22(0.40)$ \\
\hline Kishanpur & 2012 & 63 & 2648 & 16 & 264 & 11 & 119 & 8 & 145 & 0.727 & $4.66(0.67)$ \\
\hline Kishanpur & 2013 & 67 & 2655 & 15 & 254 & 9 & 151 & 6 & 103 & 0.667 & $4.92(0.88)$ \\
\hline TOTALS & & 684 & 18643 & 94 & 1213 & 50 & 545 & 48 & 668 & & \\
\hline
\end{tabular}

Footnootes:

${ }^{a}$ Adult sex ratio, calculated as the number of males/ female. Measures of uncertainty are no included because mark-recapture analyses indicated we censused the population.

${ }^{\mathrm{b}}$ Density estimates from Bayesian spatially capture-recapture analyses reported in Chanchani et al., 2014 (a). 
Table 3. Bayesian $p$ values to test hypotheses about differences in fine scale occupancy of tigers across gradients of adult sex ratios and habitat connectivity. When distributions were exactly the same, the Bayesian $\mathrm{p}$ values would be 0.5 . Values $>0.5$ indicate that our hypothesis (indicated by $>$ sign) was supported, while values $<0.5$ signified our hypotheses was not supported.

Probabilities near 1 indicate the strongest support possible.

\begin{tabular}{|c|c|c|c|c|}
\hline \multirow[b]{2}{*}{ Year } & \multirow[b]{2}{*}{ State } & \multicolumn{3}{|c|}{ Hypothesis about occupancy ${ }^{\mathrm{a}} \&$ Bayesian $p$ values } \\
\hline & & $\begin{array}{l}\text { DNP>KPUR } \\
(\mathrm{MBI}>\mathrm{FBC})\end{array}$ & $\begin{array}{c}\text { KGHAT }>\text { KPUR } \\
(\text { MBSC }>\text { FBC })\end{array}$ & $\begin{array}{l}\text { DNP>KGHAT } \\
(\text { MBI }>\text { MBSC) }\end{array}$ \\
\hline 2012 & $1\left(1-\Psi-\Psi^{\prime}\right)$ & & 0.99 & \\
\hline 2013 & $1\left(1-\Psi-\Psi^{\prime}\right)$ & 0.95 & 1.00 & 0.03 \\
\hline 2012 & $2 \Psi(1-f)$ & & 0.45 & \\
\hline 2013 & $2 \Psi(1-f)$ & 0.31 & 0.21 & 0.55 \\
\hline 2012 & $3 \Psi(\mathrm{f})^{\mathrm{b}}$ & & 0.01 & \\
\hline 2013 & $3 \Psi(\mathrm{f})^{\mathrm{b}}$ & 0.01 & 0.01 & 0.43 \\
\hline 2012 & $4 \Psi^{\prime \prime}(1-\mathrm{f})$ & & 0.66 & \\
\hline 2013 & $4 \Psi^{\prime}(1-\mathrm{f})$ & 0.97 & 0.79 & 0.92 \\
\hline 2012 & $5 \Psi^{\prime}(\mathrm{f})$ & & 0.28 & \\
\hline 2013 & $5 \Psi^{\prime \prime}(\mathrm{f})$ & 0.67 & 0.40 & 0.74 \\
\hline
\end{tabular}

aDudhwa National Park (DNP) had even/ male-biased sex ratios and poor habitat connectivity. Kishanpur Wildlife Sanctuary (KPUR) had female-biased adult sex ratios and good habitat connectivity. Adult sex ratios in Katerniaghat Wildlife sanctuary (KGHAT) fluctuated between strongly male-biased and female-biased over the study period this site is connected to a PA in Nepal via a forest corridor. MBI - male-biased and isolated; FBC - female-biased and well connected; MBSC - male-biased, connected via a single corridor.

bNote that hypotheses about State 3 are that higher male-biased ASR's and lower connectivity will lead to lower habitat use in State 3 (Table 1), thus low Bayesian p-values are predicted. 


\section{Electronic Supplementary Materials}

Appendix A: Estimating abundance and $p^{*}$ (probability that an individual is captured atleast once)

Appendix B. Posterior predictive check plots showing distributions the of relative frequency of various values in a simulated data set, generated from the model.

Appendix C: Table of model selection results for open-population (CJS) models to estimate apparent survival for tigers. 